\title{
Reliability and validity of Duruoz Hand Index in carpal tunnel syndrome
}

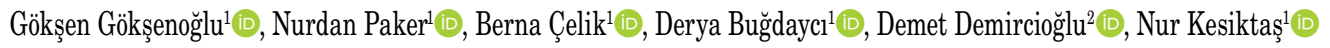 \\ 'Department of Physical Medicine and Rehabilitation, İstanbul Physical Therapy Rehabilitation Training and Research Hospital, İstanbul, Turkey \\ ${ }^{2}$ Department of Physical Medicine and Rehabilitation, İstanbul Memorial Hizmet Hospital, İstanbul, Turkey
}

Received: May 10, 2017 Accepted: October 19, 2017 Published online: July 09, 2018

\begin{abstract}
Objectives: The aim of this study is to investigate the reliability and validity of Duruoz Hand Index (DHI) in patients with carpal tunnel syndrome (CTS).

Patients and methods: A total of 55 patients ( 50 females, 5 males; mean age $51.0 \pm 10.2$ years: range, 30 to 73 years) aged $\geq 18$ years who were admitted to the outpatient clinic of a rehabilitation hospital between December 2010 and December 2012 with the diagnosis of CTS both clinically and electrophysiologically were included in this study. All patients completed DHI at baseline and repeated after a week interval. The Boston Questionnaire (BQ) and Health Assessment Questionnaire Disability Index (HAQ-DI) were filled out at baseline. And the internal consistency reliability was tested using the Cronbach's alpha. For the test-retest reliability, intraclass correlation coefficients (ICC) were calculated. The correlations between the DHI and both BQ and HAQ-DI were investigated for the construct validity.
\end{abstract}

Results: Of the patients, 41 (74.5\%) were housewives. Carpal tunnel syndrome was bilateral in 29 patients (52.7\%). The Mean Body Mass Index was $31.2 \pm 5.5 \mathrm{~kg} / \mathrm{m}^{2}$. The mean symptom duration was $22.8 \pm 23.7$ months. The mean DHI scores for the first and second evaluations were $23.25 \pm 20.64$ and $20.45 \pm 20.07$, respectively. The mean BQ symptom severity and functional status scores were $2.87 \pm 0.80$ and $2.72 \pm 1.03$, respectively. The mean HAQ-DI score was $0.91 \pm 0.66$. The Cronbach's alpha was 0.97 indicating excellent internal consistency reliability. There was a statistically significant correlation between the two measurements of DHI. The ICC value for total score was 0.88 indicating good reliability. There was a statistically significantly positive correlation between the DHI and $B Q(r=0.638, p<0.001)$. Also, DHI was significantly correlated with the HAQ-DI $(0.613, \mathrm{p}<0.001)$.

Conclusion: Our study results suggest that DHI is a reliable and valid test which can be used for evaluating hand functions in CTS patients. Keywords: Carpal tunnel syndrome; reliability; validity.

Carpal tunnel syndrome (CTS) is the most frequent upper extremity entrapment neuropathy which causes a decline in hand functions. The incidence of CTS in the general population diagnosed clinically and electrophysiologically is around 2 to $7 \% \cdot{ }^{[1]}$ Carpal tunnel syndrome is often seen between the ages 50 and 59. Since the severity of CTS increases with the advancing age, it can be considered as a progressive disorder developing in the early ages. ${ }^{[2]}$

The main complaints of patients with CTS are paresthesia and pain that occur at the fingers which innervated by the median nerve. History, physical examination, and provocative tests are useful for the diagnosis of CTS. Nerve conduction studies in accordance with the American Association of
Electrodiagnostic Medicine guidelines are helpful for the diagnosis of CTS with high specificity and sensitivity. ${ }^{[3]}$ Electrophysiological tests are also useful for the differential diagnosis. ${ }^{[4]}$ Evaluating the functional status of hand in patients with CTS is useful both for making the treatment decision, and following the results of conservative or surgical treatments. The Boston Questionnaire (BQ) is a widely used specific test for CTS. The Duruöz Hand Index (DHI) is developed for evaluating the functional status of hand in patients with rheumatoid arthritis (RA). ${ }^{[5]}$ It can be used to evaluate hand-related disability in systemic sclerosis, diabetes mellitus, stroke, and traumatic hand flexor tendon injuries. ${ }^{[6-10]}$ Although the validity and reliability of DHI have been studied in different

Corresponding author: Gökşen Gökşenoğlu, MD. İstanbul Fizik Tedavi Rehabilitasyon Ĕ̛̆itim ve Araştırma Hastanesi, Fizik Tedavi ve Rehabilitasyon Kliniği, 34186 Bahçelievler, İstanbul, Turkey. e-mail: goksengoksenoglu@hotmail.com 
diseases, to the best our knowledge, these studies do not cover CTS. Therefore, in the present study, we aimed to investigate the reliability and validity of DHI in patients with CTS.

\section{PATIENTS AND METHODS}

A total of 55 patients (50 females, 5 males; mean age $51.0 \pm 10.2$ years; range, 30 to 73 years) aged $\geq 18$ years who were admitted to the outpatient clinic of a rehabilitation hospital between December 2010 and December 2012 with the diagnosis of CTS both clinically and electrophysiologically were included in this study. The patients who had hand surgery, hand or wrist deformities, arthritis or communication problems were excluded from the study. Demographic and clinical characteristics of the patients were recorded. Severity of pain, night disturbance, and hand weakness were evaluated using a $10-\mathrm{cm}$ Visual Analog Scale (VAS). All patients were assessed by Tinel's and Phalen's tests. Moreover, all patients completed DHI and they filled out DHI at a week interval. The BQ and Health Assessment Questionnaire Disability Index (HAQ-DI) were completed at the baseline. Internal consistency of DHI was evaluated using the Cronbach's alpha. For the test-retest reliability, intraclass correlation coefficients (ICC) were calculated. For the construct validity, factor analysis was carried out. Correlation results between the DHI and BQ and HAQ-DI were assessed.

\section{Measurement tools}

\section{Duruöz Hand Index (DHI)}

The DHI was developed for evaluating the functional status of the hand in French patients with RA. ${ }^{[5]}$ It is also known as Cochin Hand Functional Disability Scale. It consists of 18 items related with the hand activities. It has five factors such as kitchen (1-8 items), dressing (2 items), personal hygiene (2 items), office tasks ( 2 items), and others (4 items). Every item has a score between $0-5$ and total score changes between 0-90. Higher scores indicate severe hand-related disability. There are French, English, and Turkish versions of the scale. The reliability and validity of DHI have been studied in hand osteoarhritis, ${ }^{[6]}$ traumatic hand flexor tendon injuries, ${ }^{[9]}$ stroke, ${ }^{[10]}$ systemic sclerosis (scleroderma), ${ }^{[7]}$ and diabetic hands.${ }^{[8]}$

\section{Boston Questionnaire (BQ)}

The BQ was developed by a group of hand surgeons, rheumatologists, and patients to assess CTS-related pain, paresthesia, numbness, weakness, nocturnal symptoms, and general functional status. ${ }^{[1]]}$ It consists of two scales: Symptom Severity Scale and Functional
Status Scale. Symptom Severity Scale has 11 questions. Functional Status Scale evaluates eight activities. Every item has a score between 1-5. Higher scores show higher disability level related with the activity. The reliability and validity of the Turkish version of the BQ have been shown. ${ }^{[12]}$

\section{Health Assessment Questionnaire Disability Index}

The HAQ is a useful test that provides information about the general state of health status. ${ }^{[13,14]}$ It is a commonly used scale to measure the functional status. It is particularly useful for assessing functional disability in daily activities. It is a self-assessment test that can also be performed by face to face interviews in clinical settings. It contains 20 items in eight domains. It evaluates the functional status of upper and lower extremities with questions about dressing, arising, eating, walking, hygiene, reach, grip, and activities. Every item has a score between 0-3. Zero shows activities can be performed easily, whereas 3 indicates that performing the activity is impossible. Each domain is scored separately. Total score can be calculated by taking the mean score of eight domains. Higher scores indicate worse functional status. The reliability and validity studies of the Turkish version of HAQ have been shown. ${ }^{[15]}$

This study was approved by the institutional Ethics Committee. An informed consent was obtained from each patient. The study was conducted in accordance with the principles of the Declaration of Helsinki.

\section{Statistical analysis}

Statistical analysis was performed using the IBM SPSS version 22.0 statistical software (IBM Corp., Armonk, NY, USA). Descriptive data were expressed in mean, standard deviation, minimum, maximum, median, frequency, and percentage. The distribution of the variables was measured using the KolmogorovSmirnov test. Repeated measurements were analyzed by the Wilcoxon test. The Cronbach's alpha, which is a useful test for determining relationships between items, was calculated for the internal consistency reliability. Intraclass correlation coefficients were calculated for the test-retest reliability. Values near 1 indicate higher test-retest reliability, while values near 0 indicate lower test-retest reliability. Confirmatory factor analysis was performed to verify the consistency between the predicted factor structure and the factor analysis with our data. The $p$ value for confirmatory factor analysis should be higher than 0.05 . The Goodness Fit Index (GFI), Confirmatory Fit Index (CFI), and 
Table 1. Demographic and clinical characteristics

\begin{tabular}{lccc}
\hline Variables & $\%$ & Median & Min-Max \\
\hline Age (year) & & 51 & $30-73$ \\
Body Mass Index $\left(\mathrm{kg} / \mathrm{m}^{2}\right)$ & & 30.5 & $21.1-45.9$ \\
Education status (year) & & 5 & $0-15$ \\
Symptom duration (months) & & 12 & $1-144$ \\
Gender & 90.9 & & \\
$\quad$ Female & 9.1 & & \\
$\quad$ Male & & & \\
Marital status & 81.8 & & \\
$\quad$ Married & 18.2 & & \\
$\quad$ Single & & & \\
Hand dominance & 96.4 & & \\
$\quad$ Right & 3.6 & \\
$\quad$ Left & & & \\
Symptomatic hand & 23.6 & \\
$\quad$ Right & 23.6 & \\
$\quad$ Left & 52.7 & \\
$\quad$ Bilateral & 81.8 & \\
Tinel's test positivity & 87.3 & \\
Phalen's test positivity & &
\end{tabular}

Normed Fit Index values should be higher than 0.90 for acceptable fit. The value of the Root Mean Square Error of Approximation (RMSEA) is interpreted as follows: $\leq 0.05$ indicates very good, $>0.05-0.08$ good, and $\geq 0.10$ poor fit. The Spearman correlation test was used to evaluate the relationship between the DHI and both BQ and HAQ-DI for construct validity of the scale. If the Spearman's correlation coefficient is closer to 1 , there is a stronger relation between the measures, whereas the values closer to 0 show a weak correlation. A $p$ value of $<0.05$ was considered statistically significant.

\section{RESULTS}

Demographic and clinical characteristics are shown in Table 1 . Of the patients, 41 (74.5\%) were housewives. In this study, CTS was bilateral in
29 patients (52.7\%). Almost all patients had right hand dominance. Provocative tests were positive in more than $80 \%$. The mean VAS pain, VAS night disturbance, and VAS weakness scores were $5.65 \pm 2.25$, $4.78 \pm 2.44$, and 3.01 \pm 2.71 , respectively.

The DHI, BQ, and HAQ-DI scores are summarized in Table 2. The mean values for the first and second measurements of DHI were $23.25 \pm 20.64$ and $20.45 \pm 20.07$, respectively. The mean Boston Symptom Severity Scale and Functional Status Scale scores were $2.87 \pm 0.80$ and $2.73 \pm 1.03$, respectively. The mean HAQ-DI score was $0.91 \pm 0.66$. Internal consistency for DHI total and factor scores are summarized in Table 3. All of the Cronbach's alpha values except office tasks item were above 90 . The Cronbach's alpha was 0.828 for office tasks. Internal consistency of DHI was high. Cronbach's alpha was 0.97 for total score of DHI.

Table 2. Duruoz Hand Index, Boston Questionnaire and Health Assessment Questionnaire Disability Index

\begin{tabular}{lccc}
\hline & Mean & Median & Min-Max \\
\hline Duruoz Hand Index & & & $0-89$ \\
$\quad$ First test & 23.25 & 19 & $0-85$ \\
$\quad$ Second test & 20.45 & 16 & $1.1-4.8$ \\
Boston Questionnaire & & & $1-5$ \\
$\quad$ Symptom Severity Scale score & 2.87 & 2.81 & $0-2.6$ \\
$\quad$ Functional Status Scale score & 2.73 & 2.75 & 0.88 \\
Health Assessment Questionnaire Disability Index & 0.91 & & \\
\hline
\end{tabular}


Table 3. Cronbach's alpha values for the internal consistency of Duruoz Hand Index

\begin{tabular}{lcc}
\hline & Cronbach's Alpha & Number of Questions \\
\hline Duruoz Hand Index & & \\
Total & 0.973 & 18 \\
Kitchen & 0.937 & 8 \\
Dressing & 0.937 & 2 \\
Personal hygiene & 0.916 & 2 \\
Office tasks & 0.828 & 2 \\
Other & 0.908 & 4 \\
\hline
\end{tabular}

Table 4. Intraclass correlation coefficients for the test-retest reliability of Duruoz Hand Index

\begin{tabular}{lccccc}
\hline & $\mathrm{r}$ & \multicolumn{3}{c}{$95 \%$ Confidence Interval } & $p$ \\
\hline Duruoz Hand Index & & & & & \\
$\quad$ Total & 0.881 & 0.796 & - & 0.931 & $<0.001$ \\
Kitchen & 0.896 & 0.822 & - & 0.939 & $<0.001$ \\
Dressing & 0.816 & 0.685 & - & 0.893 & $<0.001$ \\
Personal hygiene & 0.883 & 0.799 & - & 0.932 & $<0.001$ \\
Office tasks & 0.881 & 0.796 & - & 0.931 & $<0.001$ \\
Other & 0.793 & 0.646 & - & 0.879 & $<0.001$ \\
\hline
\end{tabular}

Table 5. Model Fit Indexes for confirmatory factor analysis

\begin{tabular}{cccccccccc}
\hline & $\chi^{2}$ & Df & $p$ & $\chi^{2} /$ Df & GFI & CFI & NFI & RMSEA \\
\hline DHI & 377.896 & 132 & $<0.001$ & 2.863 & 0.590 & 0.790 & 0.714 & 0.186 \\
\hline
\end{tabular}

$\chi^{2} / \mathrm{Df}$ : Chi-squared/ degrees of freedom; GFI: Goodness Fit Index; CFI: Comparative Fit Index; NFI: Normed Fit Index; RMSEA: Root mean square error of approximation; DHI: Duruöz Hand Index.

Table 6. Correlation results between Duruoz Hand Index and Boston Questionnaire subscales and Health Assessment Questionnaire Disability Index

\begin{tabular}{|c|c|c|c|c|c|c|}
\hline & \multicolumn{6}{|c|}{ Duruoz Hand Index } \\
\hline & Total & Kitchen & Dressing & Personal hygiene & Office tasks & Other \\
\hline \multicolumn{7}{|c|}{ Boston Questionnaire } \\
\hline \multicolumn{7}{|c|}{ Functional Status Scale } \\
\hline $\mathrm{r}$ & 0.695 & 0.704 & 0.508 & 0.484 & 0.671 & 0.614 \\
\hline $\mathrm{p}$ & 0.000 & 0.000 & 0.000 & 0.000 & 0.000 & 0.000 \\
\hline \multicolumn{7}{|c|}{ Symptom Severity Scale } \\
\hline $\mathrm{r}$ & 0.519 & 0.551 & 0.363 & 0.386 & 0.474 & 0.407 \\
\hline $\mathrm{p}$ & 0.000 & 0.000 & 0.006 & 0.004 & 0.000 & 0.002 \\
\hline \multicolumn{7}{|c|}{ Total } \\
\hline $\mathrm{r}$ & 0.638 & 0.665 & 0.448 & 0.440 & 0.614 & 0.536 \\
\hline $\mathrm{p}$ & 0.000 & 0.000 & 0.001 & 0.001 & 0.000 & 0.000 \\
\hline \multicolumn{7}{|c|}{ HAQ-DI } \\
\hline $\mathrm{r}$ & 0.613 & 0.637 & 0.529 & 0.359 & 0.570 & 0.523 \\
\hline $\mathrm{p}$ & 0.001 & 0.000 & 0.004 & 0.060 & 0.002 & 0.004 \\
\hline
\end{tabular}

HAQ-DI: Health Assessment Questionnaire Disability Index; Spearman Correlation. 
Intraclass correlation coefficients (ICC) are shown in Table 4. All of the values except other activities were above 0.8. The ICC for other activities was 0.793 . Test-retest reliability of DHI was high. There was a statistically significant correlation between the two measurements of DHI total and factor scores.

The results of the confirmatory factor analysis are summarized in Table 5. The $\chi^{2} / \mathrm{Df}$ value was $<3(\mathrm{p}<0.001)$. Our model met the condition for good fit. However, the GFI, CFI, NFI, RMSEA values were $<0.90$. The GFI, CFI, NFI, and RMSEA values did not meet the condition for good conformity. The correlations between DHI and BQ as well as HAQ-DI subscales are shown in Table 6. A statistically significantly positive correlation was found between the DHI and $\mathrm{BQ}$ $(\mathrm{p}<0.001)$. The DHI was significantly correlated with the HAQ-DI $(p=0.001)$. The Spearman's correlation coefficients for the relationship between DHI and BQ total score and HAQ-DI were over 0.6.

\section{DISCUSSION}

In this study, the DHI is found as a reliable and valid test in CTS. The DHI was correlated very well with the subscales and total score of BQ. There was a very good correlation between the DHI and HAQ-DI total score and the subscale scores except for the personal hygiene area. Similarly, Yücel and Seyithanoğlu ${ }^{[16]}$ reported a statistically significant correlation between DHI and $B Q$ in a group of patients who had carpal tunnel release surgery.

In a previous study including 89 patients with hand osteoarthritis, the interobserver reliability of DHI was reported as excellent. ${ }^{[6]}$ In the aforementioned study, the authors concluded that the validity of DHI was also good, as shown by significant correlations with the Revel's Functional Index, Dreiser's Functional Index, and handicap as measured by VAS. Moreover, they suggested that hand-related functional status was improved in the seven-month follow-up period after surgery. The good responsiveness of DHI was also reported in another study. ${ }^{[17]}$ These results are consistent with out findings. However, the responsiveness of DHI was not assessed in our study.

Brower and Poole ${ }^{[7]}$ concluded that DHI was a reliable test in which ICC values differed between 0.81 and 0.97 for the test-retest reliability in systemic sclerosis. The validity of DHI in systemic sclerosis was studied by the significant correlation results between DHI and Keital Function test, Arthritis Hand Function test, HAQ in the aforementioned study.
In a previous study including patients with diabetes mellitus, the DHI was reported to be a valid test for the assessment of hand disability, as a result of the significant correlation results between DHI and Hand Functional Index, VAS, Hand Disability and Pins tests. ${ }^{[8]}$ In another study, excellent test-retest reliability for DHI was reported by the value of 0.99 for ICC in flexor tendon injuries of the hand. A good internal consistency reliability was also reported by the value of 0.87 Cronbach's alpha in the same study. In addition, significant correlation results between the DHI and disabilities of arm, shoulder and hand questionnaire (DASH), VAS for handicap and hand functions were reported. ${ }^{[9]}$ In another study, it was concluded that DHI had an excellent test-retest reliability, as shown by the value of 0.99 for ICC in stroke patients. The Cronbach's alpha was reported as 0.97 in the same study. A strong correlation was reported between DHI and self-care domain of Functional Independence Measurement (FIM) in term of construct validity. ${ }^{[10]}$

In the $\mathrm{BQ}$ functional status scale, there are questions related with hand functions in eight domains. Each item is assessed on a five point-scale. One indicates completing the activity without difficulty, whereas five indicates that the activity is impossible to perform. In DHI, each item is scored on a total of six points. Therefore, the DHI may provide more detailed information about the hand functions. There are some differences in terms of the activities which are assessed in both tests. Writing, buttoning up, and opening a jar are common activities that are inquired in both BQ and DHI. In BQ, there are also items which evaluate bathing and dressing. However, in the DHI, there is no item related to bathing. On the other hand, in the DHI, there is an extra zipping question related with dressing. In DHI, hand functions are questioned in detail for kitchen work. Since most of the CTS patients are female as in our study, detailed questions on kitchen work are useful for measuring and following the functional impairment. Along with that, three out of four of the patients were housewives in this study, thus, the importance of thorough housework assessment, brushing teeth, opening the door, using scissors were also asked in the DHI. In the BQ, bathing, reading, holding a phone, carrying a shopping bag and doing house work were asked. In the HAQ-DI, dressing up, rising up, eating, walking, hygiene, reach, grip and some usual activities related to both upper and lower extremities were assessed on a four-point scale. The HAQ-DI is a widely used test; however, it is not a specific test for evaluating hand-related disability. 
Another advantage for the use of DHI as a reliable and a valid test in CTS patients is that it may be sometimes an extraarticular manifestation of RA. Carpal tunnel syndrome has been reported in $2.8 \%$ of patients with RA in a previous retrospective study ${ }^{[18]}$ The CTS incidence is about 4.18 per 1,000 person-years according to another study. ${ }^{[19]}$ Since CTS can be seen in patients with RA, DHI can be advantageous, particularly in the patients with both CTS and RA. Using DHI for various hand problems make the functional impairment due to these different conditions comparable. The DHI has a three factor-structure. Confirmatory factor analysis revealed that $\chi^{2} / \mathrm{Df}$ value was $<3(\mathrm{p}<0.001)$ which shows that model fit is acceptable. However, the values $<0.90$ belong to GFI, CFI, NFI, and RMSEA did not meet the criteria of good fit due to the relatively small sample size.

In this study, the mean DHI scores for CTS patients were found to be 23.25 and 20.45 in the first and last tests, respectively. In a previous study, the DHI scores for a group of patients with hand osteoarthritis were found to be $16.39 \pm 13.49(0-52){ }^{[6]}$ In other studies, DHI scores were reported as $21.10 \pm 19.25(0-66)$ for systemic sclerosis patients; $5.80 \pm 9.58$ for diabetic hand patients; $40.45 \pm 17.71$ for the patients with flexor tendon trauma in hand; and $31.2 \pm 26.6$ for stroke patients. ${ }^{[7-10]}$ In this study, the disability of hand in CTS patients was found to be comparable with that of the patients with systemic sclerosis. Flexor tendon trauma causes more severe disability in hand, compared to CTS.

The strength of this study is, to the best of our knowledge, being the first study which investigates the reliability and validity of DHI in patients with CTS. However, this study has some limitations such as the lack of a power analysis to estimate the number of participants and no follow-up due to the crosssectional design; therefore, the responsiveness of DHI was unable to be investigated.

In conclusion, our study results suggest that DHI is a reliable and valid test which can be used for evaluating hand functions in CTS patients.

\section{Declaration of conflicting interests}

The authors declared no conflicts of interest with respect to the authorship and/or publication of this article.

\section{Funding}

The authors received no financial support for the research and/or authorship of this article.

\section{REFERENCES}

1. Atroshi I, Gummesson C, Johnsson R, Ornstein E, Ranstam J, Rosén I. Prevalence of carpal tunnel syndrome in a general population. JAMA 1999;282:153-8.

2. Becker J, Scalco RS, Pietroski F, Celli LF, Gomes I. Is carpal tunnel syndrome a slow, chronic, progressive nerve entrapment? Clin Neurophysiol 2014;125:642-6.

3. Nuckols T, Harber P, Sandin K, Benner D, Weng H, Shaw R, et al. Quality measures for the diagnosis and non-operative management of carpal tunnel syndrome in occupational settings. J Occup Rehabil 2011;21:100-19.

4. Keith MW, Masear V, Chung KC, Maupin K, Andary M, Amadio PC, et al. American Academy of Orthopaedic Surgeons Clinical Practice Guideline on diagnosis of carpal tunnel syndrome. J Bone Joint Surg [Am] 2009;91:2478-9.

5. Duruöz MT, Poiraudeau S, Fermanian J, Menkes CJ, Amor $B$, Dougados $M$, et al.Development and validation of a rheumatoid hand functional disability scale that assesses functional handicap. J Rheumatol 1996;23:1167-72.

6. Poiraudeau S, Chevalier X, Conrozier T, Flippo RM, Lioté F, Noël E, et al. Reliability, validity, and sensitivity to change of the Cochin hand functional disability scale in hand osteoarthritis. Osteoarthritis Cartilage 2001;9:570-7.

7. Brower LM, Poole JL. Reliability and validity of the Duruoz Hand Index in persons with systemic sclerosis (scleroderma). Arthritis Rheum 2004;51:805-9.

8. Turan Y, Duruöz MT, Aksakalli E, Gürgan A. Validation of Duruöz Hand Index for diabetic hand dysfunction. J Investig Med 2009;57:887-91.

9. Erçalik T, Şahin F, Erçalik C, Doğu B, Dalgiç S, Kuran B. Psychometric characteristics of Duruoz Hand Index in patients with traumatic hand flexor tendon injuries. Disabil Rehabil 2011;33:1521-7.

10. Sezer N, Yavuzer G, Sivrioglu K, Basaran P, Koseoglu BF. Clinimetric properties of the Duruoz hand index in patients with stroke. Arch Phys Med Rehabil 2007;88:309-14.

11. Levine DW, Simmons BP, Koris MJ, Daltroy LH, Hohl GG, Fossel AH, et al. A self-administered questionnaire for the assessment of severity of symptoms and functional status in carpal tunnel syndrome. J Bone Joint Surg [Am] 1993;75:1585-92.

12. Sezgin M, Incel NA, Serhan S, Camdeviren H, As I, Erdoğan C. Assessment of symptom severity and functional status in patients with carpal tunnel syndrome: reliability and functionality of the Turkish version of the Boston Questionnaire. Disabil Rehabil 2006;28:1281-5.

13. Bruce B, Fries JF. The Stanford Health Assessment Questionnaire: dimensions and practical applications. Health Qual Life Outcomes 2003;1:20.

14. Bruce B, Fries JF. The Stanford Health Assessment Questionnaire: a review of its history, issues, progress, and documentation. J Rheumatol 2003;30:167-78.

15. Küçükdeveci AA, Sahin H, Ataman S, Griffiths B, Tennant A. Issues in cross-cultural validity: example from the adaptation, reliability, and validity testing of a Turkish version of the Stanford Health Assessment Questionnaire. Arthritis Rheum 2004;51:14-9. 
16. Yücel H, Seyithanoğlu H. Choosing the most efficacious scoring method for carpal tunnel syndrome. Acta Orthop Traumatol Turc 2015;49:23-9.

17. Lefevre-Colau MM, Poiraudeau S, Fermanian J, Etchepare F, Alnot JY, Le Viet D, et al. Responsiveness of the Cochin rheumatoid hand disability scale after surgery. Rheumatology (Oxford) 2001;40:843-50.
18. Calgüneri M, Ureten K, Akif Oztürk M, Onat AM, Ertenli I, Kiraz S, et al. Extra-articular manifestations of rheumatoid arthritis: results of a university hospital of 526 patients in Turkey. Clin Exp Rheumatol 2006;24:305-8.

19. Lee KH, Lee CH, Lee BG, Park JS, Choi WS. The incidence of carpal tunnel syndrome in patients with rheumatoid arthritis. Int J Rheum Dis 2015;18:52-7. 